\title{
Eupatorium lindleyanum DC. sesquiterpenes fraction attenuates lipopolysaccharide-induced acute lung injury in mice
}

\author{
Chunjun Chu ${ }^{\mathrm{a}}$, Huiling Ren ${ }^{\mathrm{a}}$, Naiyu Xu ${ }^{\mathrm{a}}$, Long Xia ${ }^{\mathrm{a}}$, Daofeng $\mathrm{Chen}^{\mathrm{b}}{ }^{*}$, Jian Zhang $^{\mathrm{a}}$ * \\ ${ }^{a}$ College of Pharmaceutical Science, Soochow University, Suzhou 215123, P. R. China \\ ${ }^{b}$ Department of Pharmacognosy, School of Pharmacy, Fudan University, Shanghai 201203, P. R. China \\ (*Corresponding author.E-mail: jianzhang@suda.edu.cn,dfchen@shmu.edu.cn)
}

\begin{abstract}
Ethnopharmacological relevance: Eupatorium lindleyanum DC. is widely used for its efficiency in treating cough, tracheitis and tonsillitis. Acute lung injury (ALI) induced by lipopolysaccharide (LPS) in mice was used to investigate therapeutic effects and possible mechanism of the sesquiterpenes fraction of Eupatorium lindleyanum DC. (EUP-SQT).

Materials and methods: Mice were orally administrated with EUP-SQT (15, 30 and $60 \mathrm{mg} / \mathrm{kg}$ ) per day for 7 days consecutively before LPS challenge. The lung specimens and bronchoalveolar lavage fluid (BALF) were harvested for histopathological examinations and biochemical analysis at $6 \mathrm{~h}$ and $24 \mathrm{~h}$ after LPS challenge. The level of complement 3 (C3) and complement 3c (C3c) in serum was quantified by a sandwich ELISA kit.

Results: Pretreatment with EUP-SQT could significantly decrease lung wet-to-dry weight (W/D) ratio, nitric oxide (NO) and protein concentration in BALF, which was exhibited together with the lowered myeloperoxidase (MPO) activity, the increased superoxide dismutase (SOD) activity and down-regulation the level of tumor necrosis factor- $\alpha$ (TNF- $\alpha$ ), interleukin-6 (IL-6) and interleukin-1 $\beta$ (IL-1 $\beta$ ) in ALI model. Additionally, EUP-SQT attenuated lung histopathological changes and significantly reduced complement deposition with decreasing the level of C3and C3c in serum.

Conclusions: These results showed that EUP-SQT significantly attenuated LPS-induced ALI via reducing productions of pro-inflammatory mediators and decreasing the level of complement, indicating it as a potential therapeutic agent for ALI.
\end{abstract}

\section{Keywords}

Eupatorium lindleyanum DC.

Sesquiterpenes fraction

Lipopolysaccharide

Acute lung injury

Complement 3

\section{Introduction}

The plant Eupatorium lindleyanum DC., which showed anti-inflammatory and anti-hypertensive activities, is indigenous to China. The whole plant called "Ye-Ma-Zhui" by local residents is used for the treatment of cough and tracheitis (Editorial Committee of the Administration Bureau of Traditional Chinese Medicine, 1998). In previous studies, 
sesquiterpenes, triterpenoids and flavonoids were isolated from this plant (Wu et al., 2013). Eupatorium lindleyanum has protective effect on acute lung injury in rat induced by intravenous injection of oleic acid (Jiang et al., 2007). In our previous study, the sesquiterpenes compounds, such as eupalinolide $F$, eupalinolide $G$, eupalinolide $H$, eupalinolide $I$, eupalinolide $J$ and eupalinolide $\mathrm{K}$ had been isolated and identified from the herb (Wu et al., 2012). However, the effective substances of Eupatorium lindleyanum attenuating LPS-induced ALI and the possible mechanisms are still unknown.

Acute lung injury (ALI) and its more severe form, acute respiratory distress syndrome (ARDS) are the critical pathological condition especially in some severe infectious respiratory diseases (Yang et al., 2010). Both of them are characterized by alveolar-capillary membrane disruption, extensive leukocyte infiltration and releasing of pro-inflammatory mediators, pulmonary edema associated with proteinaceous alveolar exudates and deterioration of gas exchange, and finally respiratory failure (Zhang et al., 2008). In addition, the pathogenesis of ALI/ARDS involves the immunity damage and the over-activation of complement system(Flierl et al., 2008). It reported that complement 3 (C3) is involved with lung injury and inhibition of complement activation might be a potential therapeutic strategy (Ward, 1996; Makrides, 1998; Takahashi et al., 2011; Bosmann et al., 2012).

In the present study, we investigate therapeutic effects of the sesquiterpenes fraction of Eupatorium lindleyanum DC. (EUP-SQT) on ALI induced by LPS in mice and try to find its possible mechanism including the level of pro-inflammatory mediators, $\mathrm{C} 3$ and complement $3 \mathrm{c}$ (C3c).

\section{Materials and methods}

\subsection{Reagents}

LPS (Escherichia coli 055:B5) was purchased from Sigma-Aldrich Co., Ltd (St. Louis, MO, USA). Dexamethasone (DXM) acetate tablets (No. H33020822) were purchased from Zhejiang Xianju Pharmaceutical Co., Ltd. (Hangzhou, Zhejiang, China). Mouse TNF- $\alpha$, IL-6 and IL-1 $\beta$ ELISA kits (No. B1007233) were purchased from Shanghai Chuanfu Biotechnology Co., Ltd. (Shanghai, China). Mouse C3 and C3c ELISA kits (No. 20131001A) were purchased from Shanghai Yuanye Biotechnology Co., Ltd. (Shanghai, China). NO and bicinchoninic acid (BCA) protein assay kit, MPO and SOD determination kits were purchased from Nanjing Jiancheng Bioengineering Institute (Nanjing, Jiangsu, China). Polyclonal rabbit anti-human C3c complement (RS-0367R) was purchased from Shanghai Ruiqi Biological Technology Co., Ltd. (Shanghai, China). Sheep erythrocytes were collected in Alsevers' solution. Anti-sheep erythrocyte antibody was obtained from rabbit antiserum and kindly provided by Prof. Yunyi Zhang (Department of Pharmacology, School of Pharmacy, Fudan University, Shanghai, China). Rabbit erythrocytes were obtained from the ear vein of New Zealand white rabbits. Normal human serum (NHS) was obtained from healthy male donors (average age of 20 years). The isotonic veronal-buffered saline $\left(\mathrm{VBS}^{2+}\right.$ ) buffer contained $0.5 \mathrm{mmol} / \mathrm{L} \mathrm{Mg}^{2+}$ and $0.15 \mathrm{mmol} / \mathrm{L} \mathrm{Ca}^{2+}$. The veronal buffer saline (EGTA-VB) buffer contained $5 \mathrm{mmol} / \mathrm{L} \mathrm{Mg}^{2+}$ and $8 \mathrm{mmol} / \mathrm{L}$ EGTA. Heparin (sodium salt, 160 IU/mg) was purchased from Shanghai Aizite Biotech Co. Ltd. The solvents, acetonitrile and methanol were of HPLC grade from E. Merck (Darmstadt, Germany). Water was obtained from a Milli-Q water purification system (Millipore, Bedford, MA, USA). AB-8 macroporous adsorption resins were purchased from Baoen Adsorption-material Technology Co., Ltd (Cangzhou, Hebei, 
China). Eupalinolide F (F), eupalinolide G (G), eupalinolide H (H), eupalinolide I (I) and eupalinolide $\mathrm{K}(\mathbf{K})$ were isolated and indentified by us, the compounds were $98 \%, 98 \%, 96 \%$, 98\%, 95\% analysed by HPLC. All other reagents were of the highest quality available.

\subsection{Plant materials and preparation of EUP-SQT}

Eupatorium lindleyanum DC. was purchased from Xuyu, Jiangsu Province of China, in October of 2012. The plant material was authenticated by Prof. Daofeng Chen, Department of Pharmacognosy, School of Pharmacy, Fudan University, Shanghai, China, and the voucher specimen (NO. DFC-YMZ2012101201) was deposited at the Herbarium of Materia Medica, Department of Pharmacognosy, School of Pharmacy, Fudan University, Shanghai, China. The extraction and purification of EUP-SQT were carried out according to our previous studies. The dried leaves and stems of Eupatorium lindleyanum DC. (350 g) were extracted under reflux with $80 \% \mathrm{EtOH}(3500 \mathrm{ml})$ for $2 \mathrm{~h}$, repeated twice. After filtration, the combined $80 \% \mathrm{EtOH}$ extracts were evaporated to dryness under vacuum at $60{ }^{\circ} \mathrm{C}$. The extracts were treated by petroleum ether and AB-8 macroreticular resin. The treated-extracts were segmented by a column loading-treated ODS (Cosmsil, Japan), and then eluted with $30 \% \mathrm{MeOH}$. EUP-SQT in the column was eluted with $50 \% \mathrm{MeOH}$, and the eluting solution was evaporated to dryness at $60{ }^{\circ} \mathrm{C}(5.522 \mathrm{~g})$.

\subsection{High performance liquid chromatography (HPLC) analysis of EUP-SQT}

An Agilent (America) HPLC system, consisting of a binary pump, an online degasser and a diode array detector (DAD) was used to determine the contents of eupalinolide F, eupalinolide G, eupalinolide H, eupalinolide I and eupalinolide K. For chromatographic analysis, a YMC-PACK ODS-A $(\Phi 4.6 \mathrm{~mm} \times 250 \mathrm{~mm}, 5 \mu \mathrm{m})$ column was used at room temperature. The mobile phase was a mixture of acetonitrile (A) and water (B), using a gradient elution (0 min: 30\% A, 5 min: 30\% A, 15 min: $32 \%$ A, 25 min: 36\% A, 40 min: 36\% A, 60 min: $90 \%$ A, 80 min: $90 \%$ A); the flow rate was $1.0 \mathrm{ml} / \mathrm{min}$; the wavelength was $210 \mathrm{~nm}$. All solutions were filtered through a membrane filter $(0.45 \mu \mathrm{m})$ prior to HPLC analysis, and the injection volume was $20 \mu \mathrm{l}$. The retention times of eupalinolide F, eupalinolide G, eupalinolide $\mathrm{H}$, eupalinolide I and eupalinolide $\mathrm{K}$ were $8.936 \mathrm{~min}, 24.303 \mathrm{~min}, 14.249 \mathrm{~min}, 31.315 \mathrm{~min}$ and $10.514 \mathrm{~min}$, respectively. The chromatographic peaks of the analytes were identified by comparing their retention times and UV spectra with those of the reference standards. Six experimental points were employed for establishing a calibration curve. The regression lines for eupalinolide F, eupalinolide G, eupalinolide H, eupalinolide I and eupalinolide K were $y=63403 x-15.408\left(\mathrm{r}^{2}=0.9999\right), y=$ $24720 x-20.065\left(r^{2}=0.9999\right), y=79063 x+6.7811\left(r^{2}=0.9995\right), y=239018 x+53.303\left(r^{2}=\right.$ $0.9998)$ and $y=7913.5 x+62.857\left(r^{2}=0.9999\right)$, respectively, where $y$ is the peak area of analyse, and $x$ is the injection quantity of analyse.

\subsection{Anti-complementary activity through the classical pathway}

Based on Mayer's modified method (Mayer, 1961), sensitized erythrocytes (EAs) were prepared by incubation of $2 \%$ sheep erythrocytes $\left(4.0 \times 10^{8}\right.$ cells $\left./ \mathrm{ml}\right)$ with rabbit anti-sheep erythrocyte antibody (1: 1000) in $\mathrm{VBS}^{2+}$ (containing $0.5 \mathrm{mM} \mathrm{Mg}^{2+}$ and $0.15 \mathrm{mM} \mathrm{Ca}^{2+}$ ). Samples were dissolved in $\mathrm{VBS}^{2+}$. Guinea pig serum was used as the complement source. The 1: 60 diluted guinea pig serum was chosen to give submaximal lysis in the absence of complement inhibitors. In brief, various dilutions of tested samples $(200 \mu \mathrm{l})$ were mixed with $200 \mu \mathrm{l}$ of Guinea pig serum, 
and $200 \mu \mathrm{l}$ of EAs was added, then the mixture was incubated at $37^{\circ} \mathrm{C}$ for $30 \mathrm{~min}$. The different assay controls were incubated in the same conditions: (1) vehicle control: $200 \mu \mathrm{l}$ EAs in $400 \mu \mathrm{l}$ VBS $^{2+}$; (2) $100 \%$ lysis: $200 \mu \mathrm{l}$ EAs in $400 \mu \mathrm{l}$ ultrapure water; (3) samples background: $200 \mu \mathrm{l}$ dilution of each sample in $400 \mu \mathrm{VBS}^{2+}$. The reacted mixture was centrifuged immediately at $4{ }^{\circ} \mathrm{C}$ after incubation. Optical density of the supernatant was measured at $405 \mathrm{~nm}$ on well scan (Labsystems Dragon). Results were indicated in percentage of hemolytic inhibition. Inhibition of lysis $(\%)=100-100 \times\left(\mathrm{OD}_{\text {sample }}-\mathrm{OD}_{\text {sample background }}\right) \div \mathrm{OD}_{100 \% \text { lysis }}$.

\subsection{Anti-complement activity through the alternative pathway}

According to the method of Klerx (Klerx et al., 1983), each sample was dissolved in EGTA-VB, and various dilutions of sample were made. Each sample (150 $\mu \mathrm{l})$ was mixed with 1: 8 diluted NHS $(150 \mu \mathrm{l})$, then $200 \mu \mathrm{l}$ rabbit erythrocytes (ERs $1.0 \times 108 \mathrm{cells} / \mathrm{ml}$ ) was added. The mixture was incubated at $37^{\circ} \mathrm{C}$ for $30 \mathrm{~min}$. Cell lysis was determined as described in the section on anti-complementary activity through the alternative pathway.

\subsection{Animals}

Male Balb/c mice, about $20 \sim 22 \mathrm{~g}$, were purchased from the Center of Experimental Animals Soochow University (Suzhou, Jiangsu, China). The mice were kept in a specific pathogen free condition and received food and water ad libitum. Laboratory temperature was $24 \pm 1{ }^{\circ} \mathrm{C}$, and relative humidity was $40 \sim 80 \%$. Before experimentation, the mice were allowed to adapt to the experimental environment for a minimum of 3 days. The experimental protocols shown in this study were approved by the Animal Ethical Committee of School of Pharmacy at Soochow University.

2.7. Establishment of the ALI model and preventive regimen (Xie et al., 2012; Chi et al., 2013; Chu et al., 2014)

EUP-SQT was ground and suspended in distilled water containing $0.5 \%$ sodium carboxymethyl cellulose (CMC-Na) for administration to mice.

The mice were randomly divided into seven groups $(n=20)$ : control group, negative control group (EUP-SQT group, the animals were treated only with EUP-SQT at $60 \mathrm{mg} / \mathrm{kg}$ ), positive control group (LPS group, the animals were treated only with LPS at $2 \mathrm{mg} / \mathrm{kg}$ ), EUP-SQT-pretreated groups (LPS+ EUP-SQT group, the animals were treated with EUP-SQT at 15,30 and $60 \mathrm{mg} / \mathrm{kg}$ and then treated by LPS, respectively) and reference drug control group (LPS+DXM group, the animals were treated with DXM at $5 \mathrm{mg} / \mathrm{kg}$ after LPS). The doses of these drugs we chosen were on the basis of previous studies and our preliminary experiments.

The negative control group and EUP-SQT-pretreated groups received an intragastric injection of EUP-SQT at given doses, each mouse was administered orally once per day for 7 days consecutively. Mice of control and positive control group received the equal volume distilled water for 7 days consecutively. Mice of the reference drug control group received the equal volume distilled water for 6 days and only received DXM on day 7. On day 7, $2 \mathrm{~h}$ after EUP-SQT or DXM treatment, mice were slightly anesthetized with a $20 \%$ urethane $(4 \mathrm{ml} / \mathrm{kg})$ given intraperitoneally. Then, in experimental groups $2 \mathrm{mg} / \mathrm{kg}$ LPS was instilled intratracheally (i.t.) in $50 \mu \mathrm{NS}$ to induce lung injury and mice of control and negative control group were given $50 \mu \mathrm{NS}$. It took about $5 \sim 6 \mathrm{~min}$ per mice to induce lung injury. Animals recovered quickly from the 
procedure with only mild discomfort.

$6 \mathrm{~h}$ after LPS challenge, half of the each group mice $(n=10)$ were sacrificed and the blood samples were collected (each one was approximately $1 \mathrm{ml}$ ). The right lung was used to collect BALF, which was lavaged three times with $0.8 \mathrm{ml}$ of autoclaved NS. The left lung was used to obtain the lung W/D ratio. $24 \mathrm{~h}$ after LPS challenge, the rest mice were sacrificed. The inferior lobe of right lung was used for histopathologic evaluation. The superior lobes of right lung were used to collect BALF. The left lung was homogenized using a homogenizer.

\subsection{NO and protein analysis}

BALF was collected as previously described (Hashimoto et al., 2004). At $6 \mathrm{~h}$ after LPS challenge, mice were sacrificed by exsanguination. BALF was obtained by intratracheal instillation, each sample was centrifuged $\left(4{ }^{\circ} \mathrm{C}, 1400 \times \mathrm{g}, 10 \mathrm{~min}\right)$, and its supernatants were stored at $-80{ }^{\circ} \mathrm{C}$ for analysis of $\mathrm{NO}$ and protein levels. The content of $\mathrm{NO}$ and protein in the supernatants of the BALF $(6 \mathrm{~h})$ were measured by NO and BCA protein assay kits according to the manufacturer's instructions strictly. The intra and inter coefficient of variation, detection limit and detection range for NO assays is $2.00 \%, 5.19 \%, 1.00 \mu \mathrm{mol} / 1$ and $0-800.00 \mu \mathrm{mol} / 1\left(\mathrm{r}^{2}=0.999\right)$, the intra and inter coefficient of variation, detection limit and detection range for BCA assays is $1.80 \%, 3.32 \%, 20.00 \mu \mathrm{g} / \mathrm{ml}$ and $20.00-2000.00 \mu \mathrm{g} / \mathrm{ml}\left(\mathrm{r}^{2}=0.999\right)$.

\subsection{Lung W/D ratio}

Mice were sacrificed by exsanguination at $6 \mathrm{~h}$ after LPS challenge. The left lung was excised, blotted dry and weighed to obtain the "wet" weight, and then placed in an oven at $80{ }^{\circ} \mathrm{C}$ for $48 \mathrm{~h}$ to obtain the "dry" weight. The ratio of the wet lung to the dry lung was calculated to assess tissue edema.

\subsection{0. $C 3$ and $C 3$ c in serum analysis}

At $6 \mathrm{~h}$ after LPS challenge, the blood of mice was collected. Blood samples were coagulated at room temperature for $10 \mathrm{~min}$, and then centrifuged $\left(4^{\circ} \mathrm{C}, 1400 \times \mathrm{g}, 20 \mathrm{~min}\right)$, its supernatants (serum) were stored at $-80{ }^{\circ} \mathrm{C}$ for subsequent analysis. The levels of $\mathrm{C} 3$ and $\mathrm{C} 3 \mathrm{c}$ in serum were quantified by the sandwich ELISA kit, according to the manufacturer's instructions strictly. The intra and inter coefficient of variation for $\mathrm{C} 3$ assays is less than $15.00 \%$, less than $15.00 \%$, detection limit and detection range for $\mathrm{C} 3$ assays is less than $1.00 \mu \mathrm{g} / \mathrm{ml}$ and $0-160.00 \mu \mathrm{g} / \mathrm{ml}\left(\mathrm{r}^{2}\right.$ $=0.990)$, the C3 ELISA kit does not react with other soluble structural analogues. The intra and inter coefficient of variation for $\mathrm{C} 3 \mathrm{c}$ assays is less than $15.00 \%$, less than $15.00 \%$, detection limit and detection range for $\mathrm{C} 3 \mathrm{c}$ assays is less than $1.00 \mathrm{ng} / \mathrm{ml}$ and $0-480.00 \mathrm{ng} / \mathrm{ml}\left(\mathrm{r}^{2}=0.990\right)$, the C3c ELISA kit does not react with other soluble structural analogues.

\subsection{Assays for SOD and MPO activities}

At $24 \mathrm{~h}$ after LPS challenge, the left lungs were homogenized using a homogenizer, then they were prepared to $10 \%$ lung tissue homogenate. The tissue homogenate generated were assayed for MPO activity, which were measured by MPO determination kit using commercially available reagents according to the manufacturer's instructions. The homogenate was then centrifuged at $1400 \times \mathrm{g}$ for $10 \mathrm{~min}$ at $4{ }^{\circ} \mathrm{C}$. The supernatants obtained were used for assay of SOD activity. SOD activity was expressed as units per milligram of protein. The intra and inter coefficient of variation, 
detection limit and detection range for SOD assays is $1.70 \%, 3.52 \%, 5.00 \mathrm{U} / \mathrm{ml}$ and $5.00-122.10$ $\mathrm{U} / \mathrm{ml}\left(\mathrm{r}^{2}=0.999\right)$, the intra and inter coefficient of variation, detection limit and detection range for MPO assays is 6.66\%, 3.90\%, $2.90 \mathrm{U} / \mathrm{l}$ and 2.90-393.30 $\mathrm{U} / \mathrm{l}\left(\mathrm{r}^{2}=0.999\right)$.

\subsection{Cytokine analysis}

The levels of cytokine TNF- $\alpha$, IL- 6 and IL-1 $\beta$ in the supernatants of the BALF ( $24 \mathrm{~h}$ ) were quantified in duplication by the sandwich ELISA kit using commercially available reagents, according to the manufacturer's instructions strictly. The intra and inter coefficient of variation for TNF- $\alpha$ assays is $4.80 \%, 6.60 \%$, detection limit and detection range for TNF- $\alpha$ assays is $3.90 \mathrm{pg} / \mathrm{ml}$ and 7.80-500.00 $\mathrm{pg} / \mathrm{ml}\left(\mathrm{r}^{2}=0.999\right)$, the TNF- $\alpha$ ELISA kit does not react with CD40、CD40、 Ligand、Fas、Fas Ligand、LIF、OPG、RANK、RANK-L、TNF- $\beta$ 、TRAIL、TROY. The intra and inter coefficient of variation for IL- $1 \beta$ assays is $3.70 \%, 4.50 \%$, detection limit and detection range for IL- $1 \beta$ assays is $7.00 \mathrm{pg} / \mathrm{ml}$ and $31.20-2000.00 \mathrm{pg} / \mathrm{ml}(\mathrm{r} 2=0.999)$, the IL-1 $\beta$ ELISA kit does not react with IL-1 $\alpha$ IL-1Ra、IL-1RI、IL-1RII、IL-2、IL-3、IL-4、IL-5、IL-6、IL-7、 IL-9、IL-10、IL-10Ra、IL-11、IL-11Ra、IL-12、IL-12 p40、IL-13、IL-15、IL-20、IL-23R. The intra and inter coefficient of variation for IL-6 assays is $6.50 \%, 7.10 \%$, detection limit and detection range for IL- $1 \beta$ assays is $4.00 \mathrm{pg} / \mathrm{ml}$ and $7.80-500.00 \mathrm{pg} / \mathrm{ml}(\mathrm{r} 2=0.999)$, the IL-6 ELISA kit does not react with CT-1、gp130、IL-6sR、IL-11、LIF、OSM.

\subsection{Histological studies of lung}

After mice were sacrificed, inferior lobe of right lung tissue was immediately harvested and fixed in $4 \%$ formaldehyde. Then lung tissue was dehydrated and embedded in paraffin. Paraffin sections were stained with hematoxylin and eosin (H\&E) according to the regular staining method. Images were observed under an Olympus microscope at an original magnification of 400x (Zhang et al., 2009).

For the detection of complement deposits, the 5- $\mu \mathrm{m}$ sections were deparaffinized, rehydrated, and incubated with rabbit anti-human $\mathrm{C} 3 \mathrm{c}$ overnight at $4{ }^{\circ} \mathrm{C}$. Slices were visualized using chromogenic substrate solution 3, 3'-diaminobenzidine (DAB). All slides were imaged with CoolPix 4500 camera (Nikon) matched on a CX21 microscope (Olympus) at an original magnification of $400 \times$ (Baldwin et al., 2004).

\subsection{Statistical analysis}

All values were expressed as mean \pm S.D. To perform statistical analysis, one-way analysis of variance (ANOVA) was used. If any significant change were found, post hoc comparisons were performed using Fisher's PLSD. Statistical significance was accepted at $P<0.05$.

\section{Results}

\subsection{HPLC analysis of EUP-SQT}

As show in Figure 1, the contents of eupalinolide F, eupalinolide G, eupalinolide $\mathrm{H}$, eupalinolide I and eupalinolide $\mathrm{K}$ in EUP-SQT were 3.8\%, 31.4\%, 6.6\%, 3.3\% and 46.3\%, respectively. The content of the five sesquiterpenes in EUP-SQT was $91.4 \%$. 


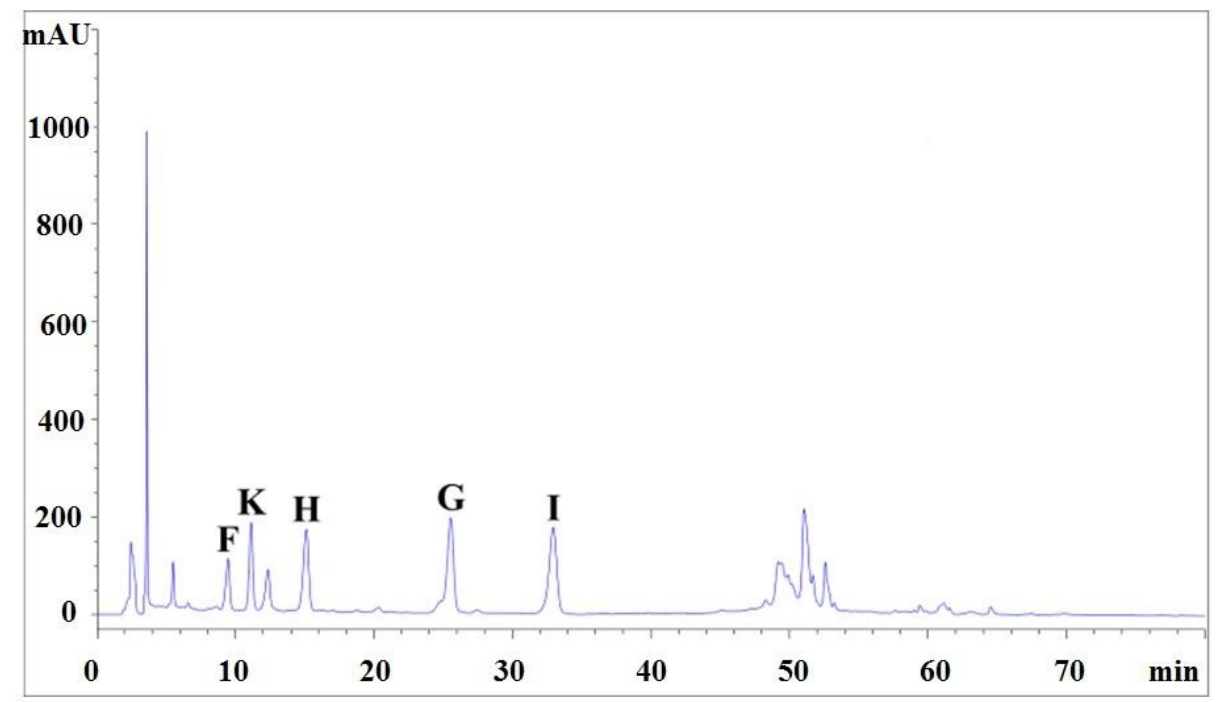

Figure 1. HPLC analysis of EUP-SQT. The chromatographic peaks of the analyses were identified by comparing their retention times and UV spectra with those of the reference standards. The chromatograms were obtained at a wavelength of $210 \mathrm{~nm}$.

\subsection{Anti-complementary activity of EUP-SQT}

As shown in Figure 2, the concentrations that resulted in 50\% hemolysis inhibition $\left(\mathrm{CP}_{50}\right)$ were $0.071 \pm 0.033 \mathrm{mg} / \mathrm{ml}$ for EUP-SQT and $0.063 \pm 0.010 \mathrm{mg} / \mathrm{ml}$ for heparin, respectively. EUP-SQT was a little weaker than heparin in inhibiting activation of the classical pathway. The concentrations that resulted in 50\% hemolysis inhibition of $\mathrm{ERs}\left(\mathrm{AP}_{50}\right)$ were $0.069 \pm 0.016 \mathrm{mg} / \mathrm{ml}$ for EUP-SQT and $0.101 \pm 0.012 \mathrm{mg} / \mathrm{ml}$ for heparin, respectively. Compared with heparin, EUP-SQT exhibited a strong inhibitory effect on the complement activation through the alternative pathway.
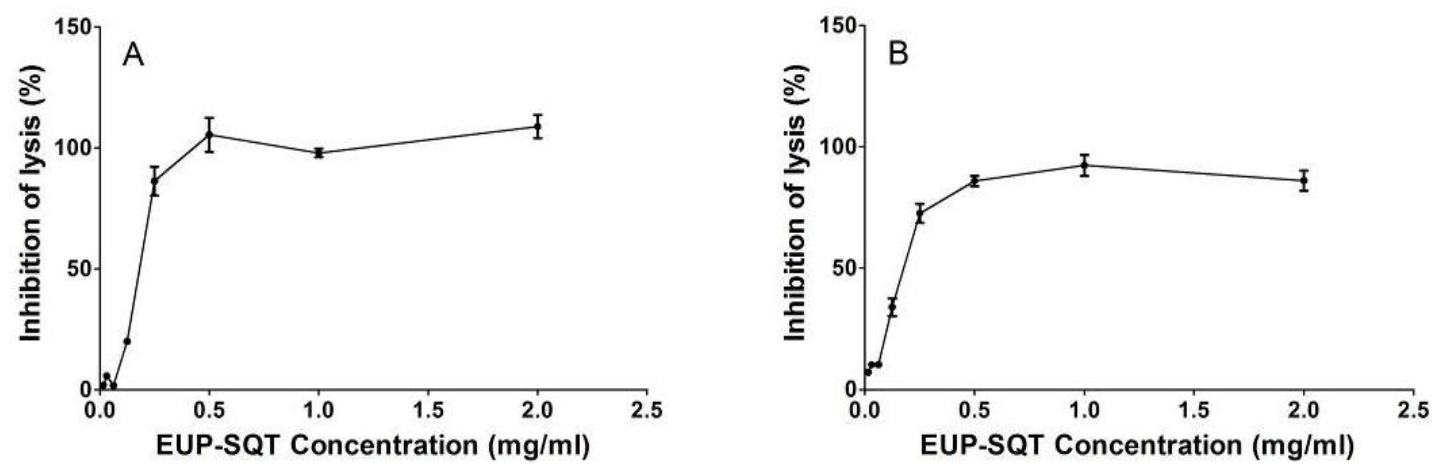

Figure 2. Anti-complementary activities of EUP-SQT. Results are expressed as hemolytic percentage (mean \pm S.D., $n=3$ ). (A) Inhibition of classical pathway-mediated hemolysis of EAs in 1: 60 diluted guinea pig serum in the presence of increasing amounts of EUP-SQT. (B) Inhibition of alternative pathway-mediated hemolysis of ERs in 1: 8 diluted NHS in the presence of increasing amounts of EUP-SQT.

\subsection{Effects of EUP-SQT on lung W/D ratio, NO and total protein concentration in BALF of mice}

As shown in Figure 3, the lung W/D ratio, NO and the total protein concentration in BALF were found to be significantly higher after LPS challenge compared with those of the control 
group $(P<0.01)$, while EUP-SQT $(60 \mathrm{mg} / \mathrm{kg}$ ) gavage itself did not cause significant changes.

Compared with vehicle treated ALI model group, EUP-SQT at 30 and $60 \mathrm{mg} / \mathrm{kg}$ markedly decreased the lung W/D ratio, NO and the total protein concentration in BALF $(P<0.05)$ (Figure $3 \mathrm{~A} \& 3 \mathrm{~B} \& 3 \mathrm{C})$. DXM also significantly decreased the lung W/D ratio, NO and the total protein concentration.
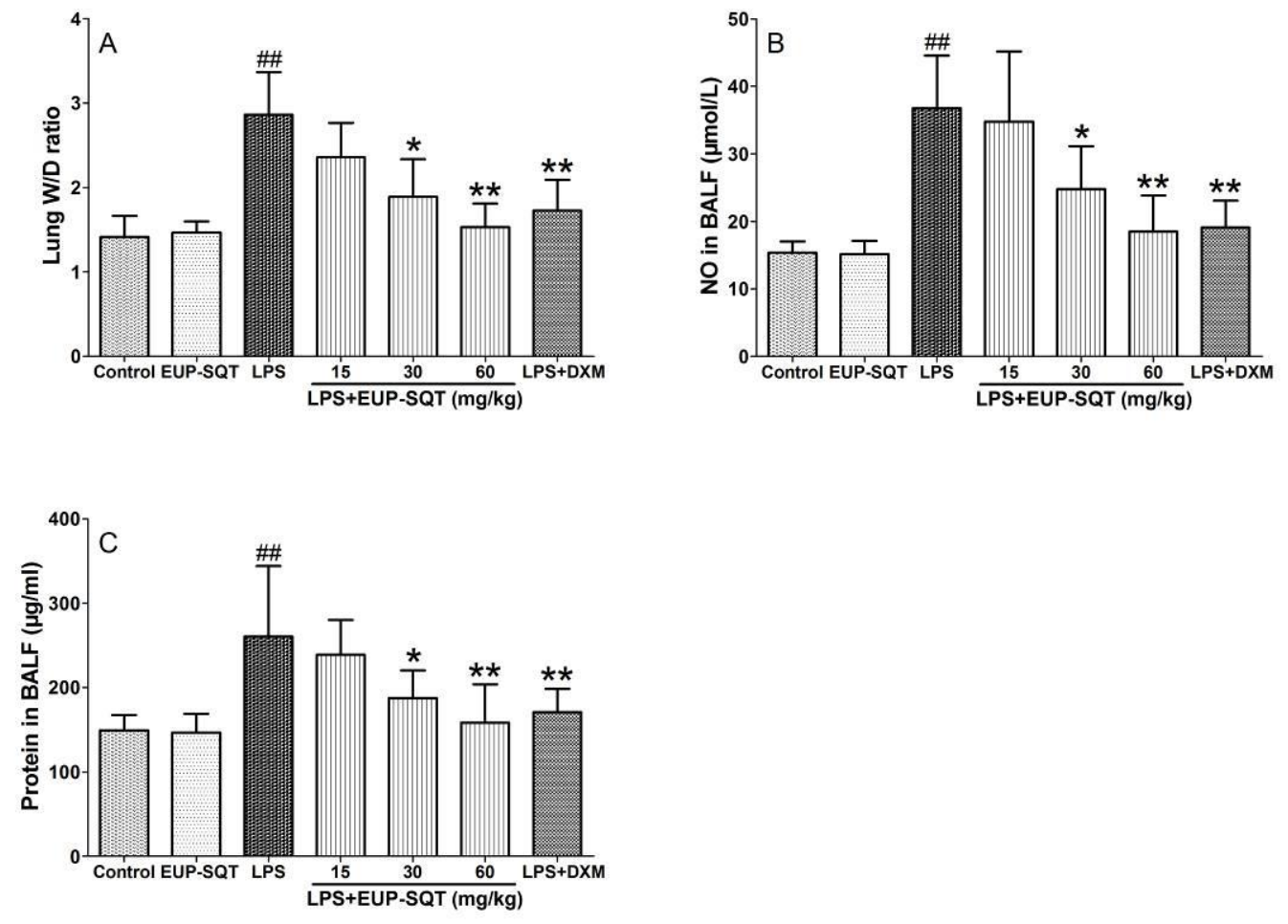

Figure 3. Effects of EUP-SQT on the lung W/D ratio (A), NO (B) and total protein concentration (C) in BALF of mice. $2 \mathrm{~h}$ after EUP-SQT pretreatment on day 7, mice were slightly anesthetized, and then $2 \mathrm{mg} / \mathrm{kg}$ LPS was instilled intratracheally (i.t.) to induce lung injury. The lung W/D ratio was determined at $6 \mathrm{~h}$ after LPS challenge; the BALF were collected at $6 \mathrm{~h}$ following LPS challenge. NO and total protein concentration in the supernatant of BALF were determined by kits recommendations. Data expressed as means \pm S.D. $(n=10) ;{ }^{\# \#} P<0.01$ compared with control, * $P<0.05$ and $* * P<0.01$ compared with vehicle treated ALI model group.

\subsection{Effect of EUP-SQT on C3 and C3c production in serum of LPS-induced ALI}

As shown in Figure 4, the levels of $\mathrm{C} 3$ and $\mathrm{C} 3 \mathrm{c}$ were significantly higher after LPS challenge compared with those of the control group $(P<0.01)$, while EUP-SQT $(60 \mathrm{mg} / \mathrm{kg})$ gavage itself did not cause significant changes.

Compared with vehicle treated ALI model group, EUP-SQT at 30 and $60 \mathrm{mg} / \mathrm{kg}$ significantly decreased the level of $\mathrm{C} 3(P<0.05)$ (Figure $4 \mathrm{~A})$, while it at $60 \mathrm{mg} / \mathrm{kg}$ markedly decreased the level of C3c $(P<0.05)$ (Figure 4B). DXM also significantly decreased the levels of C3 and C3c. 

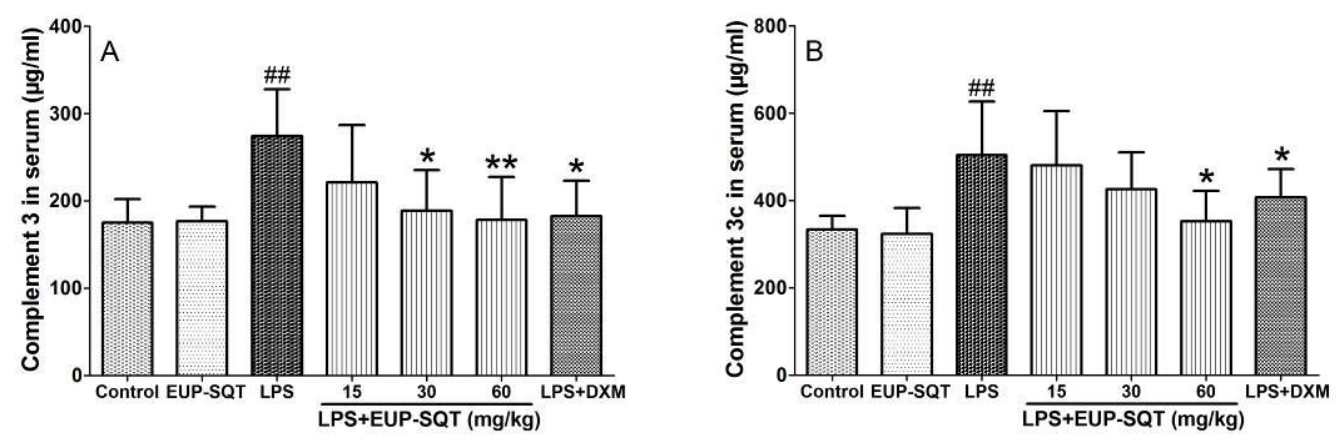

Figure 4. Effects of EUP-SQT on the levels of C3 (A) and C3c (B) in serum of mice. $2 \mathrm{~h}$ after EUP-SQT pretreatment on day 7, mice were slightly anesthetized, and then $2 \mathrm{mg} / \mathrm{kg}$ LPS was instilled intratracheally (i.t.) to induce lung injury. The serum were collected at $6 \mathrm{~h}$ following LPS challenge. $\mathrm{C} 3$ and $\mathrm{C} 3 \mathrm{c}$ concentration in serum were determined by mouse $\mathrm{C} 3$ and C3c ELISA kit Data expressed as means \pm S.D. $(n=10) ;{ }^{\#} P<0.01$ compared with control, $* P<0.05$ and $* * P$ $<0.01$ compared with vehicle treated ALI model group.

\subsection{Effects of EUP-SQT on SOD and MPO activities in lung tissues of LPS-induced ALI}

As shown in Figure 5, the SOD activity was decreased and the MPO activity was increased significantly in the model group compared with the control group $(P<0.01)$, while EUP-SQT $(60$ $\mathrm{mg} / \mathrm{kg}$ ) gavage itself did not cause significant changes.

EUP-SQT at $60 \mathrm{mg} / \mathrm{kg}$ decreased MPO activity $(P<0.01)$ (Figure 5A), while EUP-SQT at 30 and $60 \mathrm{mg} / \mathrm{kg}$ significantly increased SOD activity $(P<0.01)$ (Figure 5B). DXM also significantly increased SOD activity and decreased MPO activity.
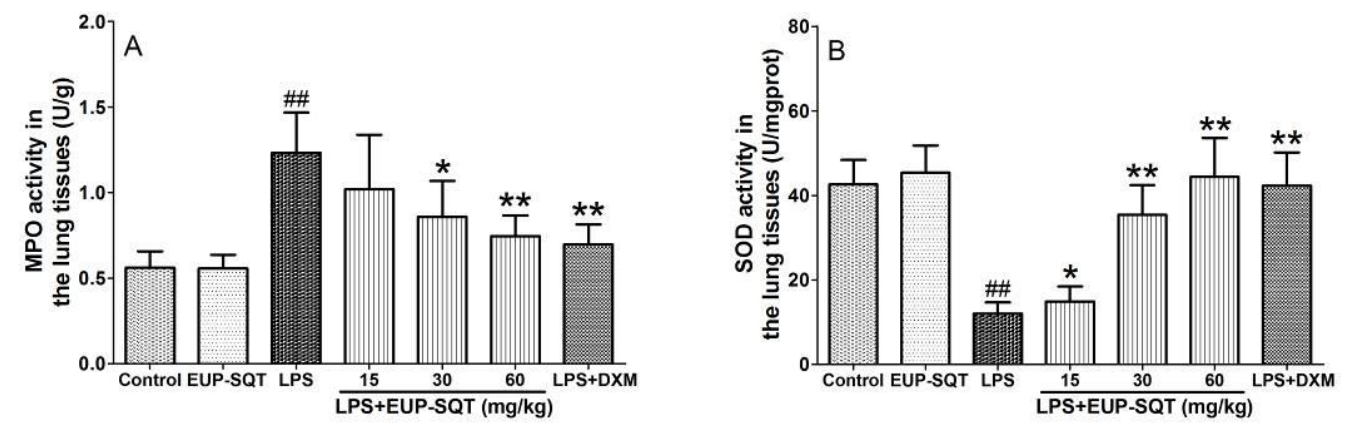

Figure 5. Effects of EUP-SQT on MPO and SOD activities of lung tissue in mice. $2 \mathrm{~h}$ after EUP-SQT pretreatment on day 7, mice were slightly anesthetized, and then $2 \mathrm{mg} / \mathrm{kg}$ LPS was instilled intratracheally (i.t.) to induce lung injury. Lung homogenates were prepared at $24 \mathrm{~h}$ after LPS challenge. MPO and SOD activities were determined by kits. Data expressed as means \pm S.D. $(n=10) ;{ }^{\#} P<0.01$ compared with control, $* P<0.05$ and $* * P<0.01$ compared with vehicle treated ALI model group.

\subsection{Effects of EUP-SQT on TNF- $\alpha, I L-6$ and IL-1 $\beta$ production in BALF}

As shown in Figure 6, LPS significantly increased TNF- $\alpha$, IL-6 and IL-1 $\beta$ production compared with the control group $(P<0.01)$, while EUP-SQT $(60 \mathrm{mg} / \mathrm{kg})$ gavage itself did not 
cause significant changes.

Compared with vehicle treated ALI model group, pretreatment with EUP-SQT markedly decreased the level of IL-6 in the BALF of mice $(P<0.05)$ (Figure 6B). EUP-SQT at 30 and 60 $\mathrm{mg} / \mathrm{kg}$ significantly reduced the level of TNF- $\alpha$ and IL- $1 \beta$ in the BALF $(P<0.05)$ (Figure 6A\&6C). DXM also significantly decreased TNF- $\alpha$, IL-6 and IL-1 $\beta$ production.
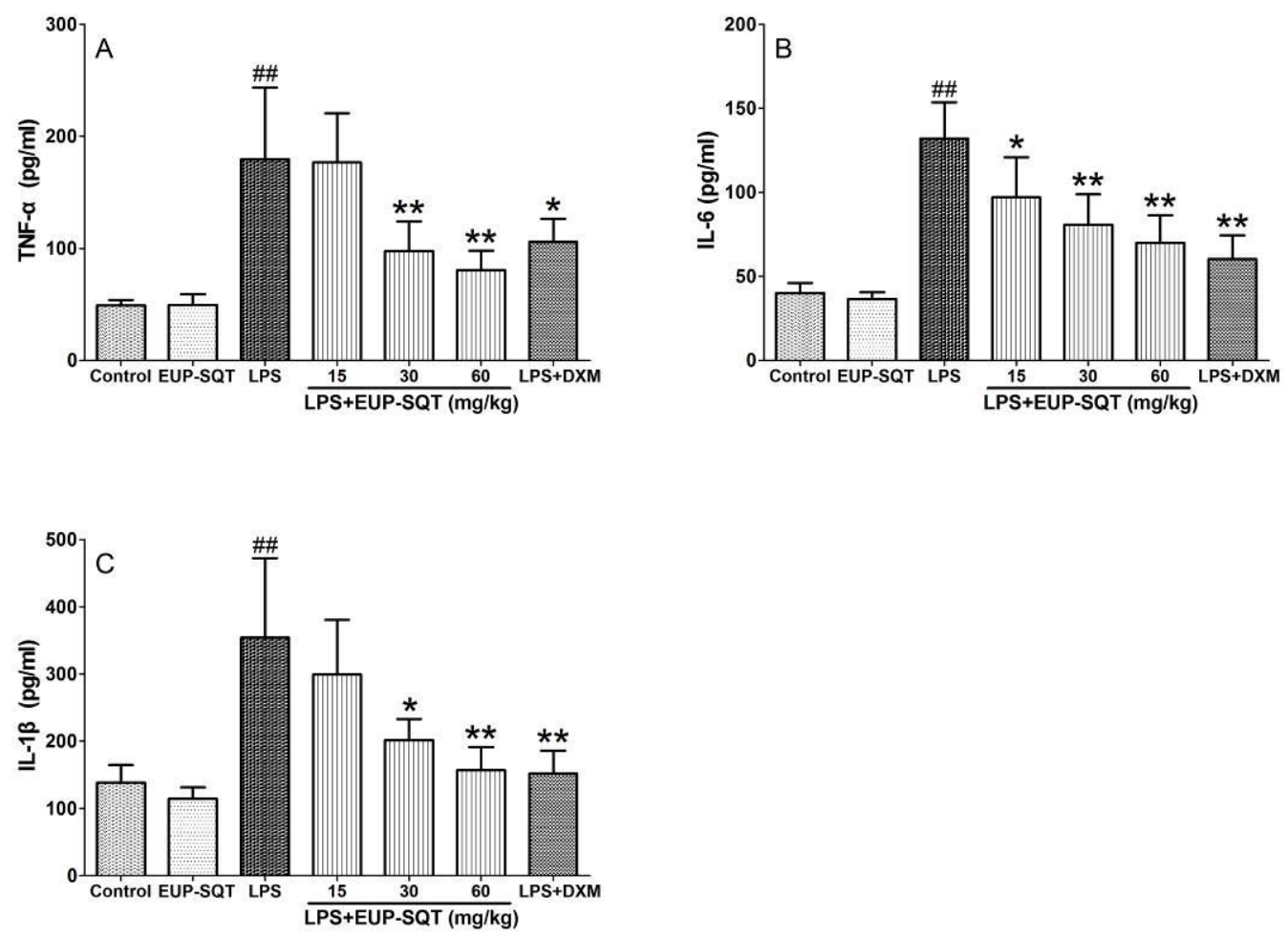

Figure 6. Effects of EUP-SQT on production of inflammatory cytokine TNF- $\alpha$, IL-6 and IL-1 $\beta$ in BALF of mice. $2 \mathrm{~h}$ after EUP-SQT pretreatment on day 7, mice were slightly anesthetized, and then $2 \mathrm{mg} / \mathrm{kg}$ LPS was instilled intratracheally (i.t.) to induce lung injury. BALF was collected at $24 \mathrm{~h}$ following LPS challenge. The levels of TNF- $\alpha$, IL- 6 and IL- $1 \beta$ in the supernatants of BALF were determined by mouse ELISA kits. Data expressed as means \pm S.D. $(n=10)$; ${ }^{\# \#} P<0.01$ compared with control, $* P<0.05$ and $* * P<0.01$ compared with vehicle treated ALI model group.

\subsection{Effect of EUP-SQT on lung histology}

Histopathological changes of each group were observed by histochemical staining with H\&E. Histopathological changes such as lung edema, increased alveolar wall thickness, inflammatory cells aggregation, pulmonary hemorrhage were observed in model group mice induced by LPS given intratracheally. As shown in Figure 7, these lesions were not apparent in control group stimulated with only NS. Pretreatment with EUP-SQT markedly ameliorated the pulmonary injury.

For vehicle treated ALI model group, immunohistochemistry of lung tissue sections showed a patchy dense immunoperoxidase indicative of complement deposition. Complement, appeared by bulk deposition, and was mainly deposited in lung tissue. In contrast, mice in control group had little complement deposition in lung tissue. Pretreatment with EUP-SQT markedly decreased 
complement deposition (Figure 7). 
$\mathrm{H} \& \mathrm{E}$

Complement

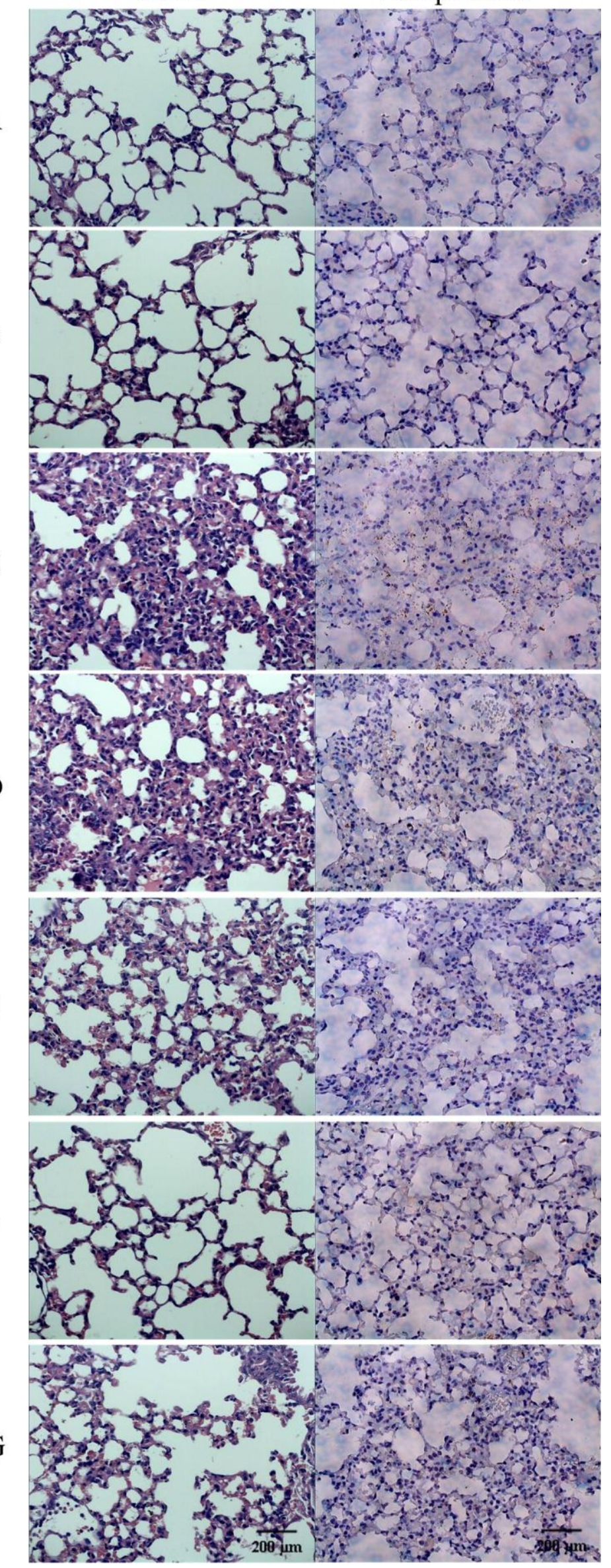


Figure 7. Hematoxylin and eosin-stained (H\&E) $(400 \times)$ and immunohistochemistry of lung tissue $(400 \times)$. Lungs from each group were processed for histological evaluation at $24 \mathrm{~h}$ after LPS challenge: Section of control (A) and EUP-SQT (B) groups mice: normal lung tissue sections (H\&E and complement). Section of a LPS-induced ALI model (C) group mouse: note increased alveolar wall thickness, inflammatory cells aggregation, pulmonary hemorrhage (H\&E) and a patchy dense immunoperoxidase indicative of complement deposition (complement). Section from 15, 30 and $60 \mathrm{mg} / \mathrm{kg}$ EUP-SQT-pretreated (D, E, F, respectively) and DXM-treated (G) groups mouse: note mild alveolar wall thickness, reduced inflammatory cells aggregation, little pulmonary hemorrhage (H\&E) and little complement deposition (complement).

\section{Discussion}

Eupatorium lindleyanum DC. is the authentic and superior medicinal herbal of Jiangsu Province in China, called "Ye-Ma-Zhui" by local residents. Ye-Ma-Zhui Syrup produced by Jiangsu Ange Pharmaceutical Co., Ltd. is used for the treatment of chronic bronchitis, cough and phlegm. In our studies, the ethanol extract (EUP-EtOH) of Ye-Ma-Zhui could attenuate LPS-induced ALI which was accepted by West China Journal of Pharmaceutical Sciences. The trichloromethane fraction and the ethyl acetate fraction of EUP-EtOH could also attenuate LPS-induced ALI, and the main compounds of ethyl acetate extract were the sesquiterpenes analysized by HPLC. So EUP-SQT was prepared and the results showed EUP-SQT significantly attenuated LPS-induced ALI.

In our study, an animal model of direct ALI was established and used by i.t. instillation of LPS in mice (Xie et al., 2012; Chi et al., 2013), because LPS is the important inducer of ALI (Wu et al., 2002) which can elicit strong inflammatory (Saluk-Juszczak et al., 2005) and immune (Pulendran et al., 2001) response in animals. DXM was used as a positive control to evaluate the anti-inflammatory efficiency of EUP-SQT in LPS-induced ALI, which is the most frequently used anti-inflammatory drugs in the clinical treatment of ALI/ARDS (Meduri et al., 2002).

In our investigation(Chu et al., 2014), we selected time points which data is stable and significantly different from the control group as the monitoring point in time. Therefore, $6 \mathrm{~h}$ after LPS challenge we measured NO and total protein in BALF, C3 and C3c in serum, obtained the lung W/D ratio. $24 \mathrm{~h}$ after LPS challenge we measured TNF- $\alpha$, IL- 6 and IL-1 $\beta$ in BALF, MPO and SOD in lung tissue homogenate, carried out histopathologic evaluation.

We evaluated the lung wet-to-dry weight ratio to quantify the magnitude of pulmonary edema, which is a typical symptom of inflammation (Kalyan Kumar et al., 2011) and a major characteristic of ALI (Yang et al., 2010). As other indexes of epithelial and endothelial permeability in ALI, we measured the total protein content in the BALF (Beck et al., 1982).

NO has well been demonstrated in the pathophysiology and development of ALI induced by LPS (Huffman et al., 2003). Oxidative stress plays an important role in the development of LPS-induced ALI. MPO could act as an index to reflect the activation, adhesion, and recruitment of neutrophils into lung (Klebanoff, 2005). The activity variation of SOD may represent degree of tissue injury (Macarthur et al., 2000). In our experiment, EUP-SQT reduced the productions of NO in BALF, which might contribute to the amelioration of inflammatory response and the lessened lung damage. EUP-SQT could inhibit pulmonary parenchymal MPO activity and enhance SOD activity, suggesting EUP-SQT may effectively scavenge oxyradicals during the 
inflammatory response to LPS-induced ALI.

LPS can induce the production of several inflammatory and chemotactic cytokines. Pro-inflammatory cytokines TNF- $\alpha$, IL- 6 and IL- $1 \beta$ appear in the early phase of an inflammatory response, play a critical role in the pathophysiology of inflammation in ALI, and contribute to the severity of lung injury (Giebelen et al., 2007; Chi et al., 2013). In clinical the high levels of TNF- $\alpha$, IL-6 and IL-1 $\beta$ in the BALF are detected in the patients with ALI/ARDS (Minamino et al., 2006). In our studies, LPS induced the production of large amounts of TNF- $\alpha$, IL- 6 and IL- $1 \beta$ in the BALF of mice at $24 \mathrm{~h}$ after LPS challenge, and EUP-SQT lowered the levels of TNF- $\alpha$, IL- 6 and IL-1 $\beta$. Therefore, EUP-SQT may protect against LPS-induced ALI by decreasing the production of these pro-inflammatory cytokines.

The complement system consists of more than 30 serum and cellular proteins, including positive and negative regulators, linked in three biochemical cascades, the classical, alternative and lectin complement pathways (Thiel, et al., 1997; Makrides, 1998). C3 activation leads to the entry of the final common pathway resulting in the downstream formation of the activation products, C3a,C3b, C5a, the formation of the membrane attack complex (MAC, C5b-9) (Yanai et al., 2012; Danobeitia et al.,2014). There are abundant evidences C3, C5, C5a and C5aR may regulate the inflammatory response in a variety of inflammatory responses, such as ALI, ARDS, acute vascular injury after systemic activation of complement (Bosmann et al., 2012). C3a has been shown to regulate IL-1 $\beta$ and TNF- $\alpha$ gene expression and synthesis (Mervi et al., 2000).The complement system has been strongly associated with the inflammatory response to Ischemia-reperfusion injury (IRI). Mice harboring C5aR or combined C3aR/C5aR deficiency were protected from ischemic injury at 24 and 48 hours post-reperfusion and showed significant reductions in BUN serum levels, pro-inflammatory cytokine and chemokine mRNA expression, and tissue infiltration by activated immunocytes. Tubular epithelial cells and macrophages cultured under hypoxia/reoxygenation conditions respond to $\mathrm{C} 3 \mathrm{a}$ and $\mathrm{C} 5 \mathrm{a}$ stimulation by expressing cytokines, such as IL-6, TNF- $\alpha$, and IL-8 (Danobeitia et al.,2014).

Complement 3 plays an important role in activating complement system of ALI (Ward, 1996) Animal model of ALI studies demonstrated alterations of complement 3 levels in ALI (Bosmann et al., 2012). Pretreatment of wild type mice with humanized cobra venom factor, which inactivates $\mathrm{C} 3$, decreased polymorphonuclear neutrophil (PMN) in BAL cells and reduces $\mathrm{C} 3$ deposition in the lung (Takahashi et al., 2011). C3c is the stable conversion product of $\mathrm{C} 3$, which develops out of C3 within one hour at body temperature (Garred et al., 1988). Therefore, we quantified the levels of $\mathrm{C} 3$ and $\mathrm{C} 3 \mathrm{c}$ in serum. In our research, EUP-SQT exhibited the strong inhibitory effect on the complement activation through the classical pathway and the alternative pathway, the main compounds of EUP-SQT had anti-complement activities through the classical pathway (eupalinolide $\mathrm{F} \mathrm{CP}_{50}=0.034 \pm 0.011 \mathrm{mg} / \mathrm{ml}$, eupalinolide $\mathrm{I} \mathrm{CP}_{50}=0.435 \pm 0.054 \mathrm{mg} / \mathrm{ml}$, and eupalinolide $\mathrm{K} \mathrm{CP}_{50}=0.276 \pm 0.027 \mathrm{mg} / \mathrm{ml}$ ), moreover, eupalinolide $\mathrm{K}$ exhibited the strong inhibitory effect $\left(\mathrm{AP}_{50}: 0.025 \pm 0.052 \mathrm{mg} / \mathrm{ml}\right)$ through the alternative pathway. We thought EUP-SQT could protect the lung injury by decreased the level of complement. Therefore we detected the levels of $\mathrm{C} 3$ and $\mathrm{C} 3 \mathrm{c}$ in serum following intrapulmonary challenge with LPS, we found that the levels of C3and $\mathrm{C} 3 \mathrm{c}$ in serum increased significantly at $6 \mathrm{~h}$ after LPS challenge, then at $24 \mathrm{~h}$ immunohistochemistry of lung tissue sections showed abundantly complement deposition in vehicle treated ALI model group. EUP-SQT markedly decreased complement deposition and the levels of $\mathrm{C} 3$ and $\mathrm{C} 3 \mathrm{c}$ in serum which might contribute to the attenuation of 
lung injury. At the same time EUP-SQT lowered the levels of TNF- $\alpha$, IL- 6 and IL-1 $1 \beta$. Maybe EUP-SQT lowered the levels of pro-inflammatory cytokines by decreasing the levels of C3 and C3c. We thought that inhibitors of complement may be potential adjunctive treatments for LPS-induced ALI.

In order to verify that EUP-SQT is the effective substances of EUP attenuating LPS-induced ALI, we carried out the research on therapeutic effects of EUP-SQT and EUP-EtOH on LPS-induced ALI model. EUP-SQT and EUP-EtOH could attenuate ALI, respectively. Compared with EUP-EtOH group, EUP-SQT markedly decreased the lung W/D ratio, TNF- $\alpha$ and the total protein concentration in BALF, the levels of $\mathrm{C} 3$ and $\mathrm{C} 3 \mathrm{c}$ in serum. Therefore EUP-SQT is the effective substances of EUP attenuating LPS-induced ALI.

EUP-SQT(30 and $60 \mathrm{mg} / \mathrm{kg}$ ) and DXM markedly decreased the lung W/D ratio, NO and the total protein concentration in BALF and the levels of TNF- $\alpha$, IL- 6 and IL-1 $\beta$ in the supernatants of BALF compared with vehicle treated ALI model group, but EUP-SQT (30 and $60 \mathrm{mg} / \mathrm{kg}$ ) and DXM did not show significant different effect on the lung W/D ratio, NO and the total protein concentration and the levels of TNF- $\alpha$, IL- 6 and IL-1 $\beta$. Compared with DXM, EUP-SQT(60 $\mathrm{mg} / \mathrm{kg}$ ) showed the similar effects on the activities of SOD and MPO, the levels of C3 and C3c. Therefore, EUP-SQT had the protective effect on LPS-induced lung injury similar to DXM, which could alleviate the symptoms of lung injury in mice by reducing productions of pro-inflammatory mediators, decreasing the level of complement and reducing radicals, indicating it as a potential therapeutic agent for ALI.

In conclusion, EUP-SQT attenuated LPS-induced lung injury, including reduction of lung W/D ratio, inhibition of protein level and NO over-production in BALF. In addition, EUP-SQT lowered TNF- $\alpha$, IL- 6 and IL-1 $\beta$ level in BALF in ALI mice. The increased SOD activity and inhibited MPO activity in lung tissue were also observed in EUP-SQT-pretreated ALI mice. Histological examination showed that EUP-SQT significantly ameliorated lung injury by improving lung morphology and decreasing complement deposition. Meantime, EUP-SQT obviously reduced the levels of $\mathrm{C} 3$ and $\mathrm{C} 3 \mathrm{c}$ in serum in ALI mice. The effects of EUP-SQT against ALI were related with the inhibition the production of pro-inflammatory mediators and decreasing the level of complement.

\section{Acknowledgement}

This work was financially supported by the Natural Science Foundation of Jiangsu Science (No. BK2011296), the National Science Foundation for Young Scholars of China (No. 81202882) and the Priority Academic Program Development of Jiangsu Higher Education Institutions (PAPD). The authors are grateful to Dr. Hong Li at Department of Pharmacology of Fudan University for her valuable suggestion to improve the manuscript.

\section{References}

An Editorial Committee (over 300 members) of the Administration Bureau of Traditional Chinese Medicine, 1998. Chinese Materia Medica (Zhonghua Benchao). Shanghai Science \& Technology Press 7, 839-841.

Baldwin, W.M., Armstrong, L.P., Samaniego-Picota, M., Rahimi, S., Zachary, A.A., Conte, J.V., 
Hruban, R.H., Rodriguez, E.R., 2004. Antithymocyte globulin is associated with complement deposition in cardiac transplant biopsies. Human Immunology 65, 1273-1280.

Beck, B.D., Brain, J.D., Bohannon, D.E., 1982. An in vivo hamster bioassay to assess the toxicity of particulates for the lungs. Toxicology and Applied Pharmacology 66, 9-29.

Bosmann, M., Ward, P.A., 2012. Role of C3, C5 and anaphylatoxin receptors in acute lung injury and in sepsis. Advances in Experimental Medicine and Biology 946, 147-159.

Chi, G.F., Wei, M.M., Xie, X.X., Soromou, L.W., Liu, F., Zhao, S.H., 2013. Suppression of MAPK and NF-kappa $B$ pathways by Limonene contributes to attenuation of lipopolysaccharide-induced inflammatory responses in acute lung injury. Inflammation 36, 501-511.

Chu, C.J., Xu, N.Y., Li, X.L., Xia, L., Zhang, J., Liang, Z.T., Zhao, Z.Z, Chen, D.F., 2014. Rabdosia japonica var. glaucocalyx flavonoids fraction attenuates lipopolysaccharide-induced acute lung injury in mice. Evidence-Based Complementary and Alternative Medicine ID 894515, 12 pages.

Danobeitia1 S.J., Djamali A., Fernandez A.L., 2014. The role of complement in the pathogenesis of renal ischemia-reperfusion injury and fibrosis. Fibrogenesis \& Tissue Repair 7, 16.

Flierl, M.A., Rittirsch, D., Sarma, J.V., Huber-Lang, M., Ward, P.A., 2008. Adrenergic regulation of complement-induced acute lung injury. Advances in Experimental Medicine and Biology 632, 93-103.

Garred P., Mollnes T. E., Lea T., 1988. Quantification in enzymelinked immunosorbent assay of a C3 neoepitope expressed on activated human complement factor C3. Scandinavian Journal of Immunology 3, 329-335.

Giebelen, I.A., van Westerloo, D.J., LaRosa, G.J., de Vos, A.F., van der Poll, T., 2007. Local stimulation of alpha7 cholinergic receptors inhibits LPS-induced TNF-alpha release in the mouse lung. Shock 28, 700-703.

Hashimoto, N., Kawabe, T., Imaizumi, K., Hara, T., Okamoto, M., Kojima, K., Shimokata, K., Hasegawa, Y., 2004. CD40 Plays a Crucial Role in Lipopolysaccharide-Induced Acute Lung Injury. American Journal of Respiratory Cell and Molecular Biology 30, 808-815.

Huffman, L.J., Prugh, D.J., Millecchia, L., Schuller, K.C., Cantrell, S., Porter, D.W., 2003. Nitric oxide production by rat bronchoalveolar macrophages or polymorphonuclear leukocytes following intratracheal instillation of lipopolysaccharide or silica. Journal of Biosciences 28, 29-37.

Jiang Z.,Yang H., He H.X., Zhou Y.D., 2007. Protective Effects of Eupatorium Lindleyanum on Acute Lung Injury in Rats. China Pharmacy 27, 2094-2096.

Kalyan Kumar, G., Dhamotharan, R., Kulkarni, N.M., Mahat, M.Y., Gunasekaran, J., Ashfaque, M., 2011. Embelin reduces cutaneous TNF-alpha level and ameliorates skin edema in acute and chronic model of skin inflammation in mice. European Journal of Pharmacology 662, 63-69.

Klebanoff, S.J., 2005. Myeloperoxidase: friend and foe. Journal of Leukocyte Biology 77, 598-625.

Klerx J.P, Beukelman C.J, Van D.H, Willers J.M., 1983. Microassay for colorimetric estimation of complement activity in guinea pig, human and mouse serum. Journal of Immunological Methods 2, 215-220.

Macarthur, H., Westfall, T.C., Riley, D.P., Misko, T.P., Salvemini, D., 2000. Inactivation of 
catecholamines by superoxide gives new insights on the pathogenesis of septic shock. Proceedings of the National Academy of Sciences 97, 9753-9758.

Makrides, S.C., 1998. Therapeutic inhibition of the complement system. Pharmacological Reviews 50, 59-87.

Mayer, M.M., 1961. Complement and complement fixation, in: Kabat, E.A., Mayer, M.M. (Eds.), Experimental Immunochemistry. Springfield Publications, pp. 133-240.

Meduri, G.U., Tolley, E.A., Chrousos, G.P., Stentz, F., 2002. Prolonged methylprednisolone treatment suppresses systemic inflammation in patients with unresolving acute respiratory distress syndrome: evidence for inadequate endogenous glucocorticoid secretion and inflammation-induced immune cell resistance to glucocorticoids. American Journal of Respiratory and Critical Care Medicine 165, 983-991.

Mervi N.M., Anna-Maija T., Seppo M., 2000. Complement C3 Cleavage and Cytokines Interleukin- $\beta$ and Tumor Necrosis Factor- $\alpha$ in Otitis Media With Effusion. The Laryngoscope 10, 1745-1749.

Minamino, T., Komuro, I., 2006. Regeneration of the endothelium as a novel therapeutic strategy for acute lung injury. Journal of Clinical Investigation 116, 2316-2319.

Pulendran, B., Kumar, P., Cutler, C.W., Mohamadzadeh, M., Van Dyke, T., Banchereau, J., 2001. Lipopolysaccharides from distinct pathogens induce different classes of immune responses in vivo. Journal of Immunology 167, 5067-5076.

Saluk-Juszczak, J., Wachowicz, B., 2005. The proinflammatory activity of lipopolysaccharide. Postepy Biochemii 51, 280-287.

Takahashi, K., Saha, D., Shattino, I., Pavlov, V.I., Stahl, G.L., Finnegan, P., Melo, M.F.V., 2011. Complement 3 is involved with ventilator-induced lung injury. International Immunopharmacology 11, 2138-2143.

Thiel S., VorupJensen T., Stover C.M., Schwaeble W., Laursen S.B., Poulsen K., Willis A.C., Eggleton P., Hansen S., Holmskov U., Reid K.B., Jensenius J.C., 1997. A second serine protease associated with mannan-binding lectin that activates complement. Nature 386, 506-510.

Ward, P. A., Role of complement, chemokines, \& regulatory cytokines in acute lung injury [J]. Ann. N.Y. Acad. Sci., 1996, 796 (1): 104-112.

Wu, S.Q., Xia L., Yao S., Han H.Y., Zhang J., 2013. Advances on chemical constituents and pharmacological effects of Eupatorium lindleyanum DC.. China Pharmacy. 15, 1426-1428.

Wu, S.Q., Xu, N.Y., Sun, Q., Han, H.Y., Zhang, J., 2012. Six New Sesquiterpenes from Eupatorium lindleyanum. Helvetica Chimica Acta 9, 1637-1644.

Wu, Y., Singer, M., Thouron, F., Alaoui-El-Azher, M., Touqui, L., 2002. Effect of surfactant on pulmonary expression of type IIA PLA (2) in an animal model of acute lung injury. American Journal of Physiology-Lung Cellular and Molecular Physiology 282, L743-L750.

Xie, J.Y., Di, H.Y., Li, H., Cheng, X.Q., Zhang, Y.Y., Chen, D.F., 2012. Bupleurum chinense DC polysaccharides attenuates lipopolysaccharide-induced acute lung injury in mice. Phytomedicine 19, 130-137.

Yanai, R., Thanos, A., and Connor, K. 2012. Complement Involvement in Neovascular Ocular Diseases. Advances in Experimental Medicine and Biology 946, 161-183.

Yang, J., Qu, J.M., Summah, H., Zhang, J., Zhu, Y.G., Jiang, H.N., 2010. Protective effects of imipramine in murine endotoxin-induced acute lung injury. European Journal of 
Pharmacology 638, 128-133.

Zhang, H.Q., Wang, H.D., Lu, D.X., Qi, R.B., Wang, Y.P., Yan, Y.X., Fu, Y.M., 2008. Berberine inhibits cytosolic phospholipase A2 and protects against LPS-induced lung injury and lethality independent of the alpha2-adrenergic receptor in mice. Shock 29, 617-622.

Zhang, X.M., Song, K.J., Xiong, H.Z., Li, H.Y., Chu, X., Deng, X.M., 2009. Protective effect of florfenicol on acute lung injury induced by lipopolysaccharide in mice. International Immunopharmacology 9, 1525-1529.

$\begin{array}{cc}\text { Abbreviations } & \text { Eupatorium lindleyanum DC. } \\ \text { EUP } & \text { the ethanol extract of Eupatorium lindleyanum DC. } \\ \text { EUP-EtOH } & \text { lipopolysaccharide } \\ \text { EUP-SQT } & \text { acute lung injury } \\ \text { LPS } & \text { the bronchoalveolar lavage fluid } \\ \text { ALI } & \text { complement } 3 \\ \text { BALF } & \text { complement 3c } \\ \text { C3 } & \text { enzyme linked immunosorbent assay } \\ \text { C3c } & \text { lung wet-to-dry weight ratio } \\ \text { ELISA } & \text { myeloperoxidase } \\ \text { Lung W/D ratio } & \text { superoxide dismutase } \\ \text { MPO } & \text { bicinchoninic acid } \\ \text { SOD } & \text { acute respiratory distress syndrome } \\ \text { BCA } & \text { dexamethasone } \\ \text { ARDS } & \text { Nitric oxide } \\ \text { DXM } & \text { veronal buffer saline } \\ \text { NO } & \text { sensitized erythrocytes } \\ \text { VBS } & \text { hematoxylin and eosin } \\ \text { EAs } & \end{array}$


Eupatorium lindleyanum DC. sesquiterpenes fraction attenuates lipopolysaccharide-induced acute lung injury in mice

\begin{abstract}
Ethnopharmacological relevance: Eupatorium lindleyanum DC. is widely used for its efficiency in treating cough, tracheitis and tonsillitis. Acute lung injury (ALI) induced by lipopolysaccharide (LPS) in mice was used to investigate therapeutic effects and possible mechanism of the sesquiterpenes fraction of Eupatorium lindleyanum DC. (EUP-SQT).

Materials and methods: Mice were orally administrated with EUP-SQT (15, 30 and $60 \mathrm{mg} / \mathrm{kg}$ ) per day for 7 days consecutively before LPS challenge. The lung specimens and bronchoalveolar lavage fluid (BALF) were harvested for histopathological examinations and biochemical analysis at $6 \mathrm{~h}$ and $24 \mathrm{~h}$ after LPS challenge. The level of complement 3 (C3) and complement $3 \mathrm{c}(\mathrm{C} 3 \mathrm{c})$ in serum was quantified by a sandwich ELISA kit.

Results: Pretreatment with EUP-SQT could significantly decrease lung wet-to-dry weight (W/D) ratio, nitric oxide (NO) and protein concentration in BALF, which was exhibited together with the lowered myeloperoxidase (MPO) activity, the increased superoxide dismutase (SOD) activity and down-regulation the level of tumor necrosis factor- $\alpha$ (TNF- $\alpha$ ), interleukin-6 (IL-6) and interleukin-1 $\beta$ (IL-1 $\beta$ ) in ALI model. Additionally, EUP-SQT attenuated lung histopathological changes and significantly reduced complement deposition with decreasing the level of C3and C3c in serum.

Conclusions: These results showed that EUP-SQT significantly attenuated LPS-induced ALI via reducing productions of pro-inflammatory mediators and decreasing the level of complement, indicating it as a potential therapeutic agent for ALI.
\end{abstract}




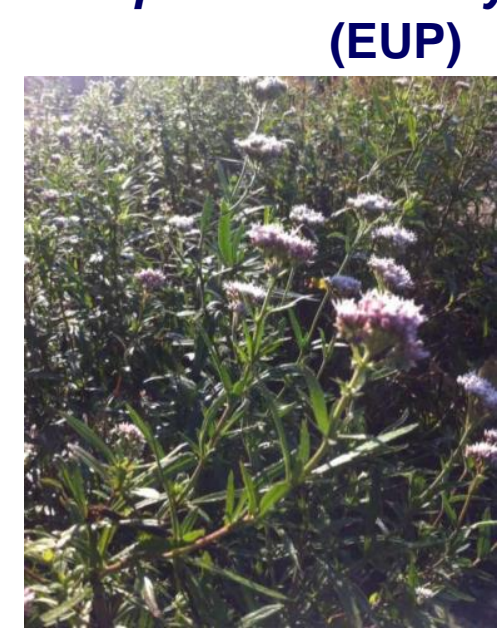

the sesquiterpenes fraction

(EUP-SQT)

Compound Content (\%)

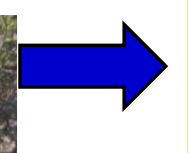

\begin{tabular}{ll}
\hline eupalinolide $F \quad 3.8$
\end{tabular}

eupalinolide $K$

46.3

eupalinolide $\mathbf{H}$

6.6

eupalinolide $\mathbf{G}$

31.4

eupalinolide I

3.3

in vitro

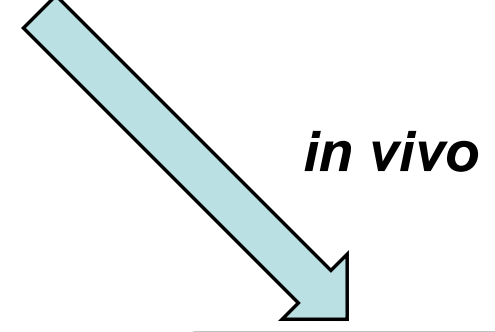

total

91.4

Anti-complementary activity

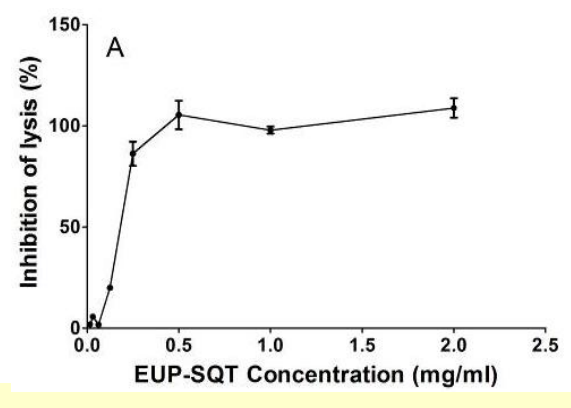

the classical pathway
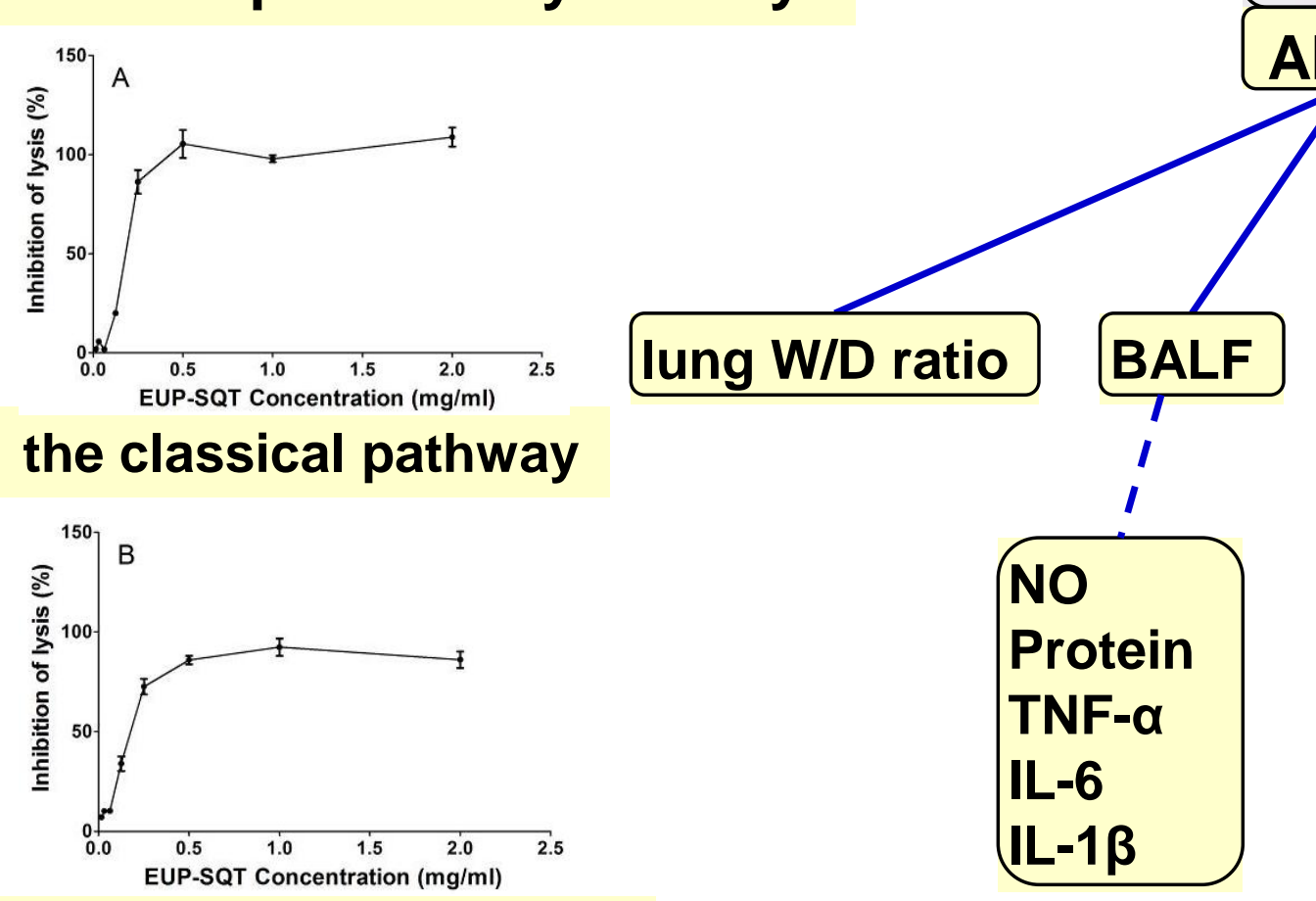

ALI model
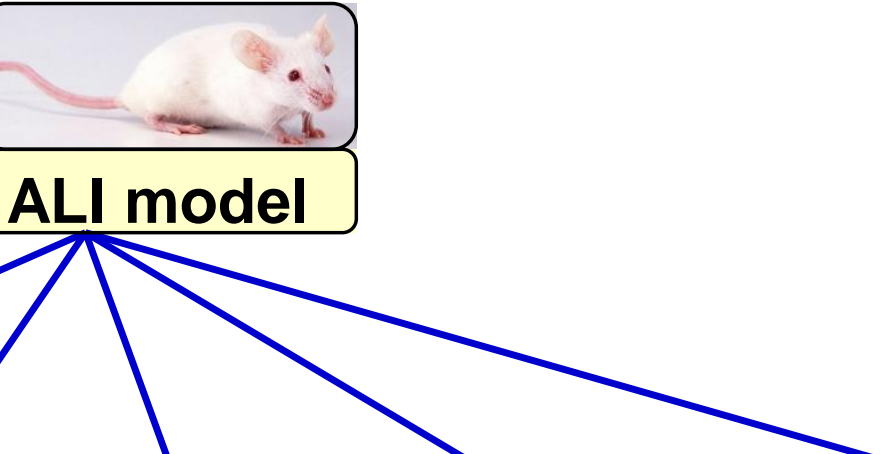

serum

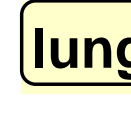

tiss

\begin{tabular}{|l|}
\multicolumn{1}{c}{ I } \\
NO \\
Protein \\
TNF- $\alpha$ \\
IL-6 \\
IL-1 $\beta$
\end{tabular}

1
C3
C3c

I

I

I

SOD

$H \& E$

C3c deposits

the alternative pathway 